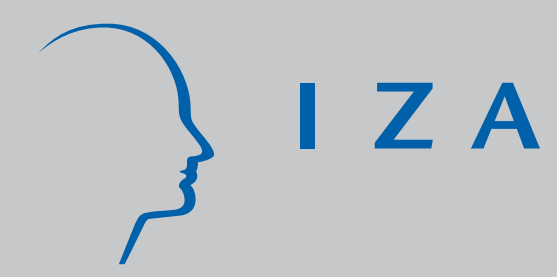

IZA DP No. 1143

High Compensation Creates a Ratchet Effect

Hans Gersbach

Amihai Glazer

May 2004 


\title{
High Compensation Creates a Ratchet Effect
}

\author{
Hans Gersbach
}

University of Heidelberg, CEPR and IZA Bonn

Amihai Glazer

University of California, Irvine

\section{Discussion Paper No. 1143 May 2004}

\author{
IZA \\ P.O. Box 7240 \\ 53072 Bonn \\ Germany \\ Phone: +49-228-3894-0 \\ Fax: +49-228-3894-180 \\ Email: iza@iza.org
}

Any opinions expressed here are those of the author(s) and not those of the institute. Research disseminated by IZA may include views on policy, but the institute itself takes no institutional policy positions.

The Institute for the Study of Labor (IZA) in Bonn is a local and virtual international research center and a place of communication between science, politics and business. IZA is an independent nonprofit company supported by Deutsche Post World Net. The center is associated with the University of Bonn and offers a stimulating research environment through its research networks, research support, and visitors and doctoral programs. IZA engages in (i) original and internationally competitive research in all fields of labor economics, (ii) development of policy concepts, and (iii) dissemination of research results and concepts to the interested public.

IZA Discussion Papers often represent preliminary work and are circulated to encourage discussion. Citation of such a paper should account for its provisional character. A revised version may be available on the IZA website (www.iza.org) or directly from the author. 
IZA Discussion Paper No. 1143

May 2004

\section{ABSTRACT}

\section{High Compensation Creates a Ratchet Effect*}

We consider a firm which pays a worker for his effort over several periods. The more the firm pays in one period, the wealthier the worker is in the following periods, and so the more he must be paid for a given effort. This wealth effect can induce an employer to pay little initially and more later on. For related reasons, the worker may work harder than the employer prefers. The incentive contracts firms offer may therefore cap the worker's earnings. Lastly, this wealth ratchet effect can induce excessive firing and turnover.

JEL Classification: $\quad$ D80, J30, J60

Keywords: principal-agent, compensation, moral hazard, wealth effects, Ratchet effects, high-powered incentives

Corresponding author:

Hans Gersbach

Alfred-Weber-Institut

University of Heidelberg

Grabengasse 14

69117 Heidelberg

Germany

Email: gersbach@uni-hd.de

\footnotetext{
*We thank Tobias Kleinschmidt and Verena Liessem for their helpful comments.
} 


\section{Introduction}

Income sometimes looks like an addiction: the more a person has, the more he demands, which is consistent with the evidence that real wages increase with age and with tenure (see, for example, Medoff and Abraham (1980) Hutchens, 1989; Altonji and Williams, 1998). For a specific example, consider the pay scale at the University of California, where professors are normally eligible for a 'merit' increase. The standard salary for a Professor I is $\$ 67,500$, with a $\$ 5,200$ increase upon rising to the rank of Professor II. But a Professor VIII (paid $\$ 118,100$ ), gets a $\$ 10,200$ salary increase upon rising to the rank of Professor IX. Professors are tenured, so the wage increases are unlikely to be designed to compensate for increased risk of firing. And the University of California has a defined benefit retirement plan, making it increasingly costly for faculty to leave as they age. So the wage pattern is unlikely designed to increase retention. Rather, it appears aimed at giving incentives for continued productivity. That raises the question of why a particular wage provides sufficient incentives in one year but not in the following year. ${ }^{1}$

The phenomenon is all the more puzzling because plausible models which consider the standard ratchet effect can lead to the opposite result. Once a high-powered incentive has revealed which workers work the most, the firm can pay them less. ${ }^{2}$

Others have, of course, addressed the problem of rising wages. As Lazear (1979) explains, and as is consistent with models of efficiency wages, the prospect of a rising wage may increase effort in the current period. But such models assume that the employer can credibly threaten to fire a low-performing worker; this assumption is often violated, as at universities dealing with tenured professors, or in corporations which

\footnotetext{
${ }^{1}$ For a psychological theory of rising wages, and evidence that job satisfaction increases with the change in the worker's pay but not with the current level of pay, see Clark (1999).

${ }^{2}$ The standard ratchet effect considers a worker who may be unwilling to work hard today, fearing that the employer may infer that the worker has a low cost of effort, and so will offer a lower wage in the future. For example, in Lazear (1986) and Gibbons (1987) the worker has private information about the firm (such as the difficulty of a job), which he is reluctant to reveal. In Aron (1987) and Kanemoto and MacLeod (1992) the worker's private information concerns a worker-specific attribute, such as ability.
} 
award golden parachutes to senior executives. Gibbons and Murphy (1992) show that when workers have career concerns (as when a firm or employer uses a worker's current output to update its belief about his ability), the optimal compensation contract would offer the strongest monetary incentives for workers close to retirement, and that the data support this relation between chief-executive compensation and stock-market performance.

A further explanation is that worker productivity rises with experience. Some empirical studies, however, show that older workers earn more than younger workers even when productivity is held constant. ${ }^{3}$

Our paper offers a different explanation for rising wages, building on principal-agent models. A firm should recognize that increasing a worker's earnings in period 1 increases his initial wealth in period 2. This increased wealth reduces the worker's marginal utility of income (and so requires the firm to pay more in period 2 for any given level of effort by the worker), and changes the worker's marginal rate of substitution between effort and income (thereby increasing the firm's marginal cost of increasing effort).

This mechanism, which can be called the wealth ratchet effect, can apply where other explanations do not, as when job mobility is low. That is, we consider a firm which profits from hiring the same worker over multiple periods. The benefits may arise from the worker acquiring firm-specific human capital, from the firm learning about the worker's characteristics (which allows the firm to allocate or design tasks to increase productivity), or from the use of efficiency wages, which give a worker an incentive to perform better. Moreover, a worker may prefer to work for the same firm over multiple periods: reasons can include the cost of searching for a job, or of moving from one job to another.

Though we focus on income, we believe the effects we consider apply more broadly. People care about other aspects of the job, say impact, fame or esteem, with the

\footnotetext{
${ }^{3}$ See, for example, Hellerstein et al. (1996), and Abowd et al. (2000).
} 
marginal utility from each declining with the amount enjoyed in the past.

One implication of the wealth ratchet effect is that firms offer incentive contracts with caps on the worker's earnings in period 1 to avoid paying high wages in the future. In contrast, high-powered incentives created, for example, by stock options would be disadvantageous. A firm which allows its workers to earn high incomes from high effort or from large capital gains will face very wealthy workers who demand even more income in the future to work hard. A second implication is excessive firing and turnover of workers. Firms protect themselves against the wealth ratchet effect by firing experienced workers even though they are more productive.

The paper proceeds as follows. The model is introduced in the next section. Section 3 examines optimal incentive contracts when a firm has incomplete monopsony power. We identify the wealth ratchet effect and show how high-powered incentives can backfire. Section 4 considers monopsony power by each firm; the wealth ratchet effect may then also create excessive worker effort. Section 5 applies our results to labor turnover and firing. Section 6 concludes. All proofs are in the appendix.

\section{The model}

We consider a two-period model. The worker's effort in period $i$ is $e_{i}$, his observable effort in period $i$ is $B_{i}$, and his initial wealth is $w$. The firm knows this initial wealth, perhaps because all workers are initially identical. The worker's income from the firm in period $i$ is $y_{i}$. The upper bound on the worker's effort in each period is $T$. To make income in period 1 affect behavior in period 2, let all goods be durable - a good bought in period 1 provides the same services in periods 1 and $2 .{ }^{4}$

The two-period incentive problem between a firm and a worker is

\footnotetext{
${ }^{4}$ The results in Fudenberg, Holmstrom, and Milgrom (1990) imply that under our assumptions a long-term contract is equivalent to a series of short-term contracts. Whereas they focus on asking whether the contract is renegotiation-proof, we focus on characterizing the contracts.
} 


\section{- Period 1}

- The firm observes wealth $w$ and offers the worker a monetary incentive schedule $y_{1}=C_{1}\left(B_{1}\right)$. The worker is paid $y_{1}$ if he produced observable output $B_{1}$ in period 1 .

- The potential worker (the agent ) accepts or rejects the contract.

- If the agent accepts $C_{1}\left(B_{1}\right)$ he exerts efforts $e_{1}$, producing output $B_{1}\left(e_{1}\right)$.

- The firm and the worker observe $B_{1}$ and the worker is paid according to the monetary incentive schedule $C_{1}\left(B_{1}\right)$. The worker's utility in that period is $U_{1}\left(w+y_{1}, T-e_{1}\right)$.

\section{- Period 2}

- The firm observes the worker's wealth , $w+y_{1}$, and offers him a monetary incentive schedule $y_{2}=C_{2}\left(B_{2}\right)$, with the same interpretation as in period 1 .

- The agent accepts or rejects the contract.

- If the agent accepts $C_{2}\left(B_{2}\right)$ he exerts effort $e_{2}$.

- The firm observes $B_{2}$ and the worker gets paid according to $C_{2}\left(B_{2}\right)$. The worker's utility in that period is $U_{2}\left(w+y_{1}+y_{2}, T-e_{2}\right)$.

Let the worker's utility function be Cobb-Douglas, with the parameter $\alpha$ satisfying $0<\alpha<1$. We then suppose that

$$
\begin{aligned}
B_{i}\left(e_{i}\right) & =b_{i} e_{i} \text { with } b_{2} \geq b_{1}>0 \\
U_{1}\left(w+y_{1}, T-e_{1}\right) & =\left(w+y_{1}\right)^{\alpha}\left(T-e_{1}\right)^{1-\alpha} \\
U_{2}\left(w+y_{1}+y_{2}, T-e_{2}\right) & =\left(w+y_{1}+y_{2}\right)^{\alpha}\left(T-e_{2}\right)^{1-\alpha} .
\end{aligned}
$$

This specification supposes that the worker cannot borrow in period 1 to smooth consumption over time. The constraint on borrowing follows naturally from the unobservability of effort, and thus from the inability of workers to commit to repayment of loans. To avoid the analysis of saving decisions, we assume that the worker buys only 
durable consumption goods. ${ }^{5}$ We normalize the price of such goods to 1 . Note that both assumptions are made for tractability. Essentially, we require that consumption increase over the lifetime. It is natural to assume that $b_{2} \geq b_{1}$; the increase can reflect technical progress or learning experience of workers. Lastly, we assume that firms can only write one-period contracts and we neglect discounting. ${ }^{6}$

That is, the firm and the worker each has a discount factor of 1. The worker's utility over the two periods is thus

$$
U_{1}\left(w+y_{1}, e_{1}\right)+U_{2}\left(w+y_{1}+y_{2}, e_{2}\right)
$$

The firm's profits in period $i$ are $\Pi_{i}$. The firm maximizes

$$
\Pi=\Pi_{1}+\Pi_{2}=b_{1} e_{1}-y_{1}+b_{2} e_{2}-y_{2}
$$

We simplify the formal exposition by assuming a tie-breaking rule that a worker who is indifferent between different effort levels chooses the profit-maximizing level.

In the following we distinguish two cases, differing by the worker's confidence that he will be hired in the following period. When the worker fears that he will be employed for only one period, the firm must offer the worker at least his reservation utility in each period. We can say that the firm has incomplete monopsony power. When the worker expects to work at the same firm over two periods (or when the firm has complete monopsony power), the firm can attract the worker by offering him a package over the two periods which yields him his reservation utility over two periods. Which assumption is more appropriate depends on the environment, and is discussed below.

\footnotetext{
${ }^{5}$ See Attanasio and Hoynes (2000) for evidence that wealth indeed increases with age.

${ }^{6}$ Though, conceptually, discounting can easily be considered, the optimal contracts become cumbersome, without generating further insights.
} 


\section{Incomplete monopsony power}

We examine first optimal incentive contracts for a firm with incomplete monopsony power. Optimal incentive contracts maximize the firm's profits subject to the participation and incentive constraints of the agent. We derive optimal incentive schedules by working backwards.

\subsection{Period 2}

The firm's contractual problem in period 2 is

$$
\begin{aligned}
& \max _{y_{2}=C_{2}\left(b_{2} e_{2}\right)}\left\{\Pi_{2}=b_{2} e_{2}-y_{2}\right\} \\
& \text { s.t. }\left(w+y_{1}+y_{2}\right)^{\alpha}\left(T-e_{2}\right)^{1-\alpha} \geq\left(w+y_{1}\right)^{\alpha} T^{1-\alpha}, I C
\end{aligned}
$$

The first constraint is the participation constraint (PC). The incentive constraint (IC) is fulfilled whenever the participation constraint is satisfied, and thus we need not consider the incentive constraint explicitly. In the Appendix we show:

\section{Proposition 1}

(i) The firm offers the incentive contract

$$
y_{2}^{0}=C_{2}\left(b_{2} e_{2}\right)=\left(w+y_{1}\right) T^{\frac{1-\alpha}{\alpha}}\left(T-e_{2}\right)^{\frac{\alpha-1}{\alpha}}-w-y_{1} .
$$

(ii) The worker chooses

$$
e_{2}^{0}=T-\left(\frac{w+y_{1}}{b_{2}}\right)^{\alpha} T^{1-\alpha}\left(\frac{1-\alpha}{\alpha}\right)^{\alpha}
$$

(iii) The firm's profits are

$$
\Pi_{2}^{0}=T b_{2}+w+y_{1}-\left(w+y_{1}\right)^{\alpha} b_{2}^{1-\alpha} T^{1-\alpha}\left\{\left(\frac{1-\alpha}{\alpha}\right)^{\alpha} \frac{1}{1-\alpha}\right\} .
$$

An immediate consequence is 


\section{Corollary 1}

The optimal contract in period 2 has the following comparative statics properties:
(i) $\frac{\partial y_{2}^{0}}{\partial\left(w+y_{1}\right)}>0$,
(ii) $\frac{\partial e_{2}^{0}}{\partial\left(w+y_{1}\right)}<0$,
(iii) $\frac{\partial \Pi_{2}^{0}}{\partial\left(w+y_{1}\right)}<0$.

The corollary exhibits the wealth ratchet effect. The higher the worker's initial wealth in period 2 , the lower his marginal utility of income, and therefore the lower his effort in period 2 and the lower the firm's profits under the optimal contract. Consequently, the firm must pay higher wages to induce a given effort by the worker.

Note that when $w+y_{1}$ is sufficiently large, the worker's optimal effort, his remuneration, and the profits of the firm all become zero. Therefore high wealth destroys any profitable transaction between the firm and the worker. In contrast, if the worker's wealth is zero $\left(w+y_{1}=0\right)$, the marginal utility of wealth becomes infinite, the disutility of work is zero, and the firm can induce the worker to exert maximal effort at zero pay. We summarize these observations in the following corollary.

\section{Corollary 2}
(i) Suppose $w+y_{1} \geq \frac{\alpha T b_{2}}{1-\alpha}$. Then, $e_{2}^{0}=0, \Pi_{2}^{0}=y_{2}^{0}=0$.
(ii) Suppose $w+y_{1}=0$. Then, $e_{2}^{0}=T, y_{2}^{0}=0, \Pi_{2}^{0}=T b_{2}$.

\subsection{Period 1}

We now turn to period 1. Note that under incomplete monopsony, in period 1 the firm must offer the worker at least his reservation utility in that period. The firm's objective in that period is

$$
\begin{aligned}
& \max _{y_{1}=C_{1}\left(b_{1} e_{1}\right)}\left\{\Pi=\Pi_{1}+\Pi_{2}^{0}\right\} \\
& \text { s.t. }\left(w+y_{1}\right)^{\alpha}\left(T-e_{1}\right)^{1-\alpha} \geq w^{\alpha} T^{1-\alpha}, I C
\end{aligned}
$$


In period 1 , the firm must be careful about the incentive constraint of the worker, as outlined below. In the Appendix we show:

\section{Proposition 2}

(i) The firm offers the incentive contract

$$
y_{1}^{0}=C_{1}\left(b_{1} e_{1}\right)= \begin{cases}\bar{y}_{1} & \text { if } \quad b_{1} e_{1}>b_{1} e_{1}^{0} \\ w T^{\frac{1-\alpha}{\alpha}}\left(T-e_{1}\right)^{\frac{\alpha-1}{\alpha}}-w & \text { if } \quad b_{1} e_{1} \leq b_{1} e_{1}^{0}\end{cases}
$$

with

$$
\begin{aligned}
& e_{1}^{0}=T-\left(b_{1}^{-1} w^{\alpha} T^{2(1-\alpha)} b_{2}^{1-\alpha}\left(\frac{1-\alpha}{\alpha}\right)^{\alpha}\right)^{\frac{1}{2-\alpha}} \\
& \bar{y}_{1}=w T^{\frac{1-\alpha}{\alpha}}\left(T-e_{1}^{0}\right)^{\frac{\alpha-1}{\alpha}}-w .
\end{aligned}
$$

(ii) The worker chooses $e_{1}^{0}$.

(iii) The firm's profits are

$$
\Pi^{0}=b_{1} e_{1}^{0}-\bar{y}_{1}+\Pi_{2}^{0}\left(\bar{y}_{1}\right)
$$

The proposition shows that the firm offers incentive contracts with caps on the worker's earnings in period 1 . The intuition follows. At $\left(e_{1}^{0}, y_{1}^{0}=\bar{y}_{1}\right)$ the firm maximizes its profits over the two periods subject to the worker's participation constraint. The lifetime utility of the worker when he chooses a particular effort level $e_{1}$ is

$$
U\left(w+y_{1}^{0}, T-e_{1}\right)+U\left(w+y_{1}^{0}, T\right)= \begin{cases}U\left(w+\bar{y}_{1}, T-e_{1}\right)+U\left(w+\bar{y}_{1}, T\right) & \text { if } e_{1}>e_{1}^{0} \\ U(w, T)+U\left(w+y_{1}^{0}\left(e_{1}\right), T\right) & \text { if } e_{1} \leq e_{1}^{0}\end{cases}
$$

Since the worker enjoys utility $U(w, T)$ in period 1 , and since $\partial y_{1}^{0} / \partial e_{1} 0$ for $e_{1}<e_{1}^{0}$, the wealth ratchet effect allows the worker to obtain the highest possible utility in period 2 , and the worker strictly prefers $e_{1}^{0}$ over any value $e_{1}<e_{1}^{0}$. The income cap at $\bar{y}_{1}$ means that a worker who increases effort beyond $e_{1}^{0}$ earns no additional income in period 1 , and benefits from no ratchet effect in period 2. For the firm, the wealth ratchet effect embodied in Proposition 2 implies

\section{Corollary 3}

Optimal contracts in period 1 have the following comparative statics properties. 
(i) $\frac{\partial e_{1}^{0}}{\partial b_{2}}<0, \frac{\partial e_{1}^{0}}{\partial b_{1}}>0$

(ii) $\frac{\partial \bar{y}_{1}}{\partial b_{2}}<0, \frac{\partial \bar{y}_{1}}{\partial b_{1}}>0$

Increased worker productivity in the future induces the firm to reduce the worker's pay and effort in period 1, with the aim of reducing the cost of high-powered incentives in period 2 .

To illustrate the distortion induced by the ratchet effect, suppose that in period 2 the firm would replace the worker of period 1 with a new worker whose wealth is $w$ who has the same productivity. Then the firm would choose in both periods the same incentive contract that we described for the period 2 problem above. Denote the period 1 contract under this scenario by $\hat{y}_{1}$ and optimal effort levels by $\hat{e}_{1}$. Optimal choices are:

$$
\begin{aligned}
& \hat{y}_{1}=w T^{\frac{1-\alpha}{\alpha}}\left(T-e_{1}\right)^{\frac{\alpha-1}{\alpha}}-w \\
& \hat{e}_{1}=T-w^{\alpha} b_{1}^{-\alpha} T^{1-\alpha}\left(\frac{1-\alpha}{\alpha}\right)^{\alpha}
\end{aligned}
$$

We can express $e_{1}^{0}$ as

$$
e_{1}^{0}=T-\left(w^{\alpha} b_{1}^{-\alpha} T^{2-2 \alpha}\left(\frac{1-\alpha}{\alpha}\right)^{\alpha}\left(\frac{b_{2}}{b_{1}}\right)^{1-\alpha}\right)^{\frac{1}{2-\alpha}}
$$

and obtain

$$
e_{1}^{0}=T-\left(\left(T-\hat{e}_{1}\right)\left(\frac{b_{2}}{b_{1}}\right)^{1-\alpha} T^{1-\alpha}\right)^{\frac{1}{2-\alpha}} .
$$

For $b_{2} \geq b_{1}$ we have

$$
e_{1}^{0}<T-\left(T-\hat{e}_{1}\right)^{\frac{1}{2-\alpha}} T^{\frac{1-\alpha}{2-\alpha}}<T-\left(T-\hat{e}_{1}\right)=\hat{e}_{1} .
$$

Hence, we obtain

\section{Corollary 4}

(i) If $b_{2} \geq b_{1}$, then $e_{1}^{0}<\hat{e}_{1}$

(ii) $\frac{\partial\left(\hat{e}_{1}-e_{1}^{0}\right)}{\partial b_{2}}>0$. 
The wealth ratchet effect induces firms to lower incentives in period 1 . The distortion increases with the worker's productivity in period 2 .

We saw that a firm which recognizes the wealth ratchet effect caps incomes. Without caps the worker would choose higher effort than is optimal for the firm. Indeed, we immediately obtain:

\section{Corollary 5}

Suppose the firm offered a worker employed over two periods the same payment schedule in the two periods. That is, in period 1 the firm offers $\hat{y}_{1}=w T^{\frac{1-\alpha}{\alpha}}\left(T-e_{1}\right)^{\frac{\alpha-1}{\alpha}}-w$ without caps; in period 2 the worker faces $y_{2}^{0}=\left(w+y_{1}\right) T^{\frac{1-\alpha}{\alpha}}\left(T-e_{2}\right)^{\frac{\alpha-1}{\alpha}}-w-y_{1}$. The worker then chooses $\hat{e}_{1}=T$ and the firm would need to pay an infinite amount.

Our result shows a disadvantage of high-powered incentives created, for example, by stock options. A firm which allows its workers to earn high incomes from high effort or from large capital gains will face very wealthy workers who will later demand even more income to work hard. Our analysis can provide a new argument why short-term stock options can backfire (see e.g. Economist 2002).

\section{Complete monopsony power}

Consider next a firm with complete monopsony power: it offers a pay schedule in period 1 which the worker anticipates will generate his reservation utility over two periods. Since the problem is complex, we simplify be setting $\alpha=1 / 2$. We consider a subgame perfect solution: in period 2 the firm offers the worker a pay schedule that induces effort and yields the worker his reservation utility in period 2. But in period 1, the worker is willing to accept utility lower than $w^{1 / 2} T^{1 / 2}$ because he knows that increased pay in period 1 leads to higher pay and utility in period 2 , namely $\left(w+y_{1}\right)^{1 / 2} T^{1 / 2}$.

Working backwards, the contractual problem of the firm in period 2 is the same as 
under incomplete monopsony power, namely

$$
\begin{aligned}
& \max _{C_{2}\left(b_{2} e_{2}\right)}\left\{\Pi_{2}=b_{2} e_{2}-y_{2}\right\} \\
& \text { s.t. }\left(w+y_{1}+y_{2}\right)^{1 / 2}\left(T-e_{2}\right)^{1 / 2} \geq\left(w+y_{1}\right)^{1 / 2} T^{1 / 2} .
\end{aligned}
$$

The solution is again characterized by $\left(y_{2}^{0}\left(e_{2}\right), e_{2}^{0}, \Pi_{2}^{0}\right)$. In period 1 the firm must offer compensation which yields the worker his reservation utility. The participation constraint is thus

$$
\left(w+y_{1}\right)^{1 / 2}\left(T-e_{1}\right)^{1 / 2}+\left(w+y_{1}+y_{2}\right)^{1 / 2}\left(T-e_{2}\right)^{1 / 2} \geq 2 w^{1 / 2} T^{1 / 2} .
$$

The firm's objective in period 1 is

$$
\begin{aligned}
& \max _{C_{1}\left(b_{1} e_{1}\right)}\left\{\Pi=\Pi_{1}+\Pi_{2}^{0}\right\} \\
& \text { s.t. }\left(w+y_{1}\right)^{1 / 2}\left(T-e_{1}\right)^{1 / 2}+\left(w+y_{1}+y_{2}\right)^{1 / 2}\left(T-e_{2}\right)^{1 / 2} \geq 2 w^{1 / 2} T^{1 / 2}, I C,
\end{aligned}
$$

where $y_{2}^{0}$ and $e_{2}^{0}$ are the optimal functions derived in proposition 1. In the Appendix we show:

\section{Proposition 3}

(i) The firm offers the incentive contract

$$
y_{1}^{*}=C_{1}\left(b_{1} e_{1}\right)= \begin{cases}\tilde{y}_{1} & \text { if } b_{1} e_{1}>b_{1} e_{1}^{*} \\ \frac{4 w T}{\left(\left(T-e_{1}\right)^{1 / 2}+T^{1 / 2}\right)^{2}}-w & \text { if } b_{1} e_{1} \leq b_{1} e_{1}^{*}\end{cases}
$$

with

$$
\begin{aligned}
e_{1}^{*} & =T-\left(\frac{-2 \sqrt{T}}{3}+\left(-\frac{q}{2}+D^{1 / 2}\right)^{1 / 3}+\left(-\frac{q}{2}+D^{1 / 2}\right)^{1 / 3}\right)^{2} \\
q & =c-\frac{2}{27} T^{3 / 2}, D=\frac{c^{2}}{4}-\frac{c}{27} T^{3 / 2}, c=-2 T w^{1 / 2}{\frac{b_{2}}{b_{1}}}^{\frac{1}{2}} \\
\tilde{y}_{1} & =\frac{4 w T}{\left(\left(T-e_{1}^{*}\right)^{1 / 2}+T^{1 / 2}\right)^{2}}-w
\end{aligned}
$$

(ii) The worker chooses $e_{1}^{*}$

(iii) The firm's profits are

$$
\Pi^{*}=b_{1} e_{1}^{*}-\tilde{y}_{1}+\Pi_{2}^{0}\left(\tilde{y}_{1}\right)
$$


As proposition 3 indicates, the incentive schedule under complete monopsony power is complex. Again the firm caps income. But because the worker has no strict incentive to exert more effort when caps are absent, the cap is less crucial than under incomplete monopsony power.

For further insight, we first make a general comparison of effort levels and then we discuss some examples. Under complete monopsony power, the wealth ratchet effect will again generate inefficiencies compared to a situation where the firm could hire a new worker in period 2. A firm which could hire a new worker in period 2 would offer in period 1 the incentive schedule $\hat{y}_{1}$ as derived in subsection 3.2 ; the associated effort is $\hat{e}_{1}$. Now the relationship between $\hat{e}_{1}$ and $e_{1}^{*}$ is ambiguous, as we discuss in the following.

We start with the following proposition, which is proved in the Appendix:

\section{Proposition 4}

(i) If $b_{2}$ is sufficiently larger than $b_{1}$ then $\hat{e}_{1}>e_{1}^{*}$

(ii) $\frac{\partial\left(\hat{e}_{1}-e_{1}^{*}\right)}{\partial b_{2}}>0$

We illustrate the relationship between $\hat{e}_{1}$ and $e_{1}^{*}$ by examples, the first having excessive effort.

\section{Example 1:}

Suppose $b_{1}=b_{2}$ and $\frac{2}{27} T^{1 / 2}=w^{1 / 2}{\frac{b_{2}}{b_{1}}}^{1 / 2}=w^{1 / 2} b_{1}^{-1 / 2}$. Then

$$
\begin{aligned}
& \hat{e}_{1}=\frac{25}{27} T \\
& e_{1}^{0}=T\left(1-\frac{\sqrt[3]{4}}{9}\right) \\
& e_{1}^{*}=T\left(1-\frac{1}{9}\left(-2+(3+2 \sqrt{2})^{1 / 3}+(3-2 \sqrt{2})^{1 / 3}\right)^{2}\right) \approx 0,99 T
\end{aligned}
$$

The example shows that the prospect of high wealth in period 2 induces excessive effort in period 1 , despite the low-powered incentive schedule. The following example illustrates the opposite case when $b_{2}$ is sufficiently larger than $b_{1}$. 


\section{Example 2:}

Suppose $b_{2}=b_{1} \cdot\left(\frac{26}{9}\right)^{2}, w^{1 / 2} b_{1}^{-1 / 2}=\frac{13}{81} T^{1 / 2}$. Then

$$
\begin{aligned}
\hat{e}_{1} & =\frac{68}{81} T \\
e_{1}^{0} & =T\left(1-\frac{13 \sqrt[3]{52}}{81}\right) \approx \frac{32}{81} T \\
e_{1}^{*} & =\frac{65}{81} T
\end{aligned}
$$

Now effort $e_{1}^{*}$ in period 1 is less than effort in the single-period case.

\section{Applications}

This section applies our results to explain particular phenomena, and explores how public policy could consider the consequences of the wealth ratchet effect.

\subsection{Excessive labor turnover and firing}

Under the assumption of incomplete monopsony we will show that the wealth ratchet effect can induce excessive firing and turnover of workers.

Suppose that learning-by-doing in period 1 increases productivity from $b_{1}$ to $b_{2}$. To benefit from this potential gain the firm must rehire the worker in period 2. But in period 2 the firm could instead hire a new worker, who would have wealth $w$ and productivity $b_{1}$. We investigate circumstances which induce the firm to fire a worker at the end of period 1 . We assume that $b_{2}>b_{1}$ and set $\alpha=1 / 2$. The firm's long-term profits, if it fires the worker at the end of period 1 , are $\Pi^{f}$; it s profits if it rehires the worker in period 2 are $\Pi^{n f}$. When the worker is fired

$$
\begin{aligned}
e_{1}^{f} & =e_{2}^{f}=T-\sqrt{\frac{w T}{b_{1}}} \\
y_{1}^{f} & =y_{2}^{f}=w T \sqrt{\frac{b_{1}}{w T}}-w \\
\Pi_{1} & =\Pi_{2}=\left(\sqrt{T b_{1}}-\sqrt{w}\right)^{2} .
\end{aligned}
$$


Accordingly,

$$
\Pi^{f}=2\left(\sqrt{T b_{1}}-\sqrt{w}\right)^{2}=2 T b_{1}-4 \sqrt{T b_{1}} \sqrt{w}+2 w
$$

When the worker in period 1 is rehired

$$
\begin{aligned}
e_{1}^{n f} & =T-\left(\frac{T}{b_{1}} \sqrt{b_{2} w}\right)^{\frac{2}{3}} \\
y_{1}^{n f} & =w T\left(\frac{b_{1}}{T \sqrt{b_{2} w}}\right)^{\frac{2}{3}}-w \\
\Pi_{1}^{n f} & =b_{1} e_{1}^{n f}-y_{1}^{n f} \\
e_{2}^{n f} & =T-\sqrt{\frac{T\left(w+y_{1}^{n f}\right)}{b_{2}}} \\
y_{2}^{n f} & =\left(w+y_{1}^{n f}\right) T\left(\frac{b_{2}}{T\left(w+y_{1}^{n f}\right)}\right)^{\frac{1}{2}}-w-y_{1}^{n f} \\
\Pi_{2}^{n f} & =T b_{2}+w+y_{1}^{n f}-2 \sqrt{\left(w+y_{1}^{n f}\right) b_{2} T} \\
\Pi^{n f} & \left.=b_{1} e_{1}^{n f}+T b_{2}+w-2 \sqrt{\left(w+y_{1}^{n f}\right.}\right) b_{2} T \\
& =T\left(b_{1}+b_{2}\right)+w-b_{1}\left(\frac{T}{b_{1}} \sqrt{b_{2} w}\right)^{\frac{2}{3}}-2\left(T^{2} b_{2} w b_{1}\right)^{\frac{1}{3}} \\
& =T\left(b_{1}+b_{2}\right)+w-3\left(T^{2} b_{1} b_{2} w\right)^{\frac{1}{3}} .
\end{aligned}
$$

In the Appendix we show:

\section{Proposition 5}

A critical value $b_{2}^{*}$ exists, with $b_{2}^{*}>b_{1}$, such that the firm fires the worker in period 1 if $b_{1} \leq b_{2}<b_{2}^{*}$.

Proposition 5 indicates that the firm fires the worker at the end of period 1, though he will be more productive in period 2. Because the wealth ratchet effect increases the pay necessary to motivate the worker, potential productivity gains arising from experience or from learning-by-doing are unrealized. Clearly, from a social point of view, in the range $b_{1}<b_{2}<b_{2}^{*}$, firing and labor turnover are excessive. The result of Proposition 5 can explain why older and wealthy workers may find it difficult to obtain jobs that guarantee their reservation utility although they are more experienced and more productive than younger workers. 


\subsection{Immediate consumption}

Our model can explain why firms may offer pay packages which induce workers to consume more in the first period, thereby reducing future wealth. One way of increasing current consumption is to substitute fringe benefits for cash salary. Such fringe benefits and amenities as travel in business class, stays at luxurious hotels, provision of health clubs at work, and so on do not increase a worker's wealth, and so do not make it more difficult for the firm to induce effort in period 2.

\section{$5.3 \quad$ Savings}

From our model, firms would prefer that workers consume their wealth rather than save or buy durable goods. Tax provisions which encourage home-buying may increase the wealth ratchet effect, whereas rules which ease access to credit cards will reduce the wealth ratchet effect. Indeed, under our view, the low savings rates in the United States may contribute to the high rate of labor force participation, high level of hours worked, and extensive use of incentive payments.

\section{Conclusion}

Our model is consistent with the existence of rising wage profiles. Of course there are other explanations. A worker's marginal product may increase with his experience, and in a competitive labor market, so will his wage. Or, as Lazear (1979) explains, and as is consistent with models of efficiency wages, the prospect of a rising wage may induce effort in the current period. But none of these models predicts a hysteresis effect, whereby an increase in income in one period causes all future incomes to rise. Our model does, and can explain why a surging stock market, which caused an executive's pay to soar in some year, could make his future pay even higher. 


\section{Appendix}

\section{Proof of proposition 1:}

The contract $C_{2}\left(b_{2} e_{2}\right)$ must satisfy the participation constraint, implying that

$$
y_{2}=\left(w+y_{1}\right) T^{\frac{1-\alpha}{\alpha}}\left(T-e_{2}\right)^{\frac{\alpha-1}{\alpha}}-w-y_{1}
$$

Maximizing $\Pi_{2}$ with respect to $e_{2}$ and using $y_{2}$ from the PC yields the first-order condition:

$$
\frac{\partial \Pi_{2}}{\partial e_{2}}=b_{2}-\left(w+y_{1}\right) T^{\frac{1-\alpha}{\alpha}}\left(T-e_{2}\right)^{-\frac{1}{\alpha}} \frac{1-\alpha}{\alpha}=0
$$

Solving yields

$$
\begin{gathered}
b_{2}\left(T-e_{2}\right)^{\frac{1}{\alpha}}=\left(w+y_{1}\right) T^{\frac{1-\alpha}{\alpha}} \frac{1-\alpha}{\alpha} \\
e_{2}^{0}=T-\left(\frac{w+y_{1}}{b_{2}}\right)^{\alpha} T^{1-\alpha}\left(\frac{1-\alpha}{\alpha}\right)^{\alpha}
\end{gathered}
$$

The firm therefore wants to achieve $e_{2}^{0}$. Using our tie-breaking rule the schedule

$$
y_{2}^{0}=C_{2}\left(b_{2} e_{2}\right)=\left(w+y_{1}\right) T^{\frac{1-\alpha}{\alpha}}\left(T-e_{2}\right)^{\frac{\alpha-1}{\alpha}}-w-y_{1}
$$

is sufficient to achieve this objective. The worker is indifferent between different effort levels and will choose $e_{2}^{0}$, and so the IC is also satisfied. Note that

$$
\begin{aligned}
& \frac{\partial e_{2}^{0}}{\partial\left(w+y_{1}\right)}<0 \\
& \frac{\partial y_{2}^{0}}{\partial\left(w+y_{1}\right)}=\left(\frac{T}{T-e_{2}}\right)^{\frac{1-\alpha}{\alpha}}-1>0
\end{aligned}
$$

Equilibrium profits are:

$$
\begin{aligned}
\Pi_{2}^{0} & =b_{2} e_{2}^{0}-y_{2}^{0} \\
& =T b_{2}-b_{2}\left(\frac{w+y_{1}}{b_{2}}\right)^{\alpha} T^{1-\alpha}\left(\frac{1-\alpha}{\alpha}\right)^{\alpha} \\
& -\left(w+y_{1}\right) T^{\frac{1-\alpha}{\alpha}}\left\{\left(\frac{w+y_{1}}{b_{2}}\right)^{\alpha} T^{1-\alpha}\left(\frac{1-\alpha}{\alpha}\right)^{\alpha}\right\}^{\frac{\alpha-1}{\alpha}}+w+y_{1} \\
& =T b_{2}+w+y_{1}-\left(w+y_{1}\right)^{\alpha} b_{2}{ }^{1-\alpha} T^{1-\alpha}\left\{\left(\frac{1-\alpha}{\alpha}\right)^{\alpha} \frac{1}{1-\alpha}\right\}
\end{aligned}
$$




\section{Proof of proposition 2:}

From the participation constraint we obtain:

$$
\left(w+y_{1}\right)^{\alpha}=w^{\alpha} T^{1-\alpha}\left(T-e_{1}\right)^{\alpha-1}
$$

We proceed in two steps. We first maximize profits of the firm subject to the participation constraint above. In the second step, we consider the incentive constraint of the worker. In the first step, we have:

$$
\begin{aligned}
& \max _{e_{1}}\left\{\Pi=\Pi_{1}+\Pi_{2}^{0}\right\} \\
& \text { s.t. }\left(w+y_{1}\right)^{\alpha}=w^{\alpha} T^{1-\alpha}\left(T-e_{1}\right)^{\alpha-1}
\end{aligned}
$$

We have

$$
\Pi=b_{1} e_{1}-y_{1}+T b_{2}+w+y_{1}-\left(w+y_{1}\right)^{\alpha} b_{2}^{1-\alpha} T^{1-\alpha}\left\{\left(\frac{1-\alpha}{\alpha}\right)^{\alpha} \frac{1}{1-\alpha}\right\}
$$

Using the participation constraint yields:

$$
\Pi=b_{1} e_{1}+T b_{2}+w-w^{\alpha} T^{2-2 \alpha} b_{2}^{1-\alpha}\left(T-e_{1}\right)^{\alpha-1}\left\{\left(\frac{1-\alpha}{\alpha}\right)^{\alpha} \frac{1}{1-\alpha}\right\}
$$

The first-order condition is

$$
\frac{\partial \Pi}{\partial e_{1}}=b_{1}-w^{\alpha} T^{2-2 \alpha} b_{2}^{1-\alpha}\left(T-e_{1}\right)^{\alpha-2}\left\{\left(\frac{1-\alpha}{\alpha}\right)^{\alpha}\right\}=0
$$

yielding

$$
e_{1}^{0}=T-\left(b_{1}^{-1} w^{\alpha} T^{2-2 \alpha} b_{2}^{1-\alpha}\left(\frac{1-\alpha}{\alpha}\right)^{\alpha}\right)^{\frac{1}{2-\alpha}}
$$

If the firm needed to take into account only the PC, it would want the worker to exert effort $e_{1}^{0}$. The associated wage according to the $\mathrm{PC}$, called $\bar{y}_{1}$, is given by

$$
\bar{y}_{1}=w T^{\frac{1-\alpha}{\alpha}}\left(T-e_{1}^{0}\right)^{\frac{\alpha-1}{\alpha}}-w
$$


In the second step, we investigate how the firm can induce the worker to choose exactly $e_{1}^{0}$. Recall that the worker's utility in period 2 will be $U\left(w+y_{1}, T\right)$. Then the twoperiod utility of the worker for a particular choice $e_{1}$ under the proposed incentive schedule is

$U\left(w+y_{1}, T-e_{1}\right)+U\left(w+y_{1}, T\right)= \begin{cases}U\left(w+\bar{y}_{1}, T-e_{1}\right)+U\left(w+\bar{y}_{1}, T\right) & \text { if } e_{1}>e_{1}^{0} \\ U(w, T)+U\left(w T^{\frac{1-\alpha}{\alpha}}\left(T-e_{1}\right)^{\frac{\alpha-1}{\alpha}}, T\right) & \text { if } e_{1} \leq e_{1}^{0}\end{cases}$

Accordingly,

$$
\frac{\partial\left\{U\left(w+y_{1}, T-e_{1}\right)+U\left(w+y_{1}, T\right)\right\}}{\partial e_{1}}\left\{\begin{array}{cc}
<0 & \text { if } e_{1}>e_{1}^{0} \\
>0 & \text { if } e_{1}<e_{1}^{0}
\end{array}\right.
$$

The worker maximizes utility by choosing $e_{1}^{0}$. A firm which caps income at $\bar{y}_{1}$ ensures that the worker's effort does not exceed $e_{1}^{0}$, and so ensures that he does not exert excessive effort with the aim of benefiting from the wealth ratchet effect in the future. Lastly, the overall profits of the firm are

$$
\Pi^{0}=b_{1} e_{1}^{0}-\bar{y}_{1}+\Pi_{2}^{0}\left(\bar{y}_{1}\right)
$$

\section{Proof of proposition 3:}

From the PC we obtain:

$$
\left(w+y_{1}\right)^{\frac{1}{2}}=\frac{2 w^{\frac{1}{2}} T^{\frac{1}{2}}}{\left(T-e_{1}\right)^{\frac{1}{2}}+T^{\frac{1}{2}}}
$$

Again, we proceed in two steps. We first maximize profits subject only to the PC. Using the PC, profits of the firm amount to:

$$
\begin{aligned}
\Pi & =b_{1} e_{1}+\Pi_{2}^{0}-y_{1} \\
& =b_{1} e_{1}+T b_{2}+w-\left(w+y_{1}\right)^{\frac{1}{2}} 2 b_{2}^{\frac{1}{2}} T^{\frac{1}{2}} \\
& =b_{1} e_{1}+T b_{2}+w-\frac{4 T w^{\frac{1}{2}} b_{2}^{\frac{1}{2}}}{\left(T-e_{1}\right)^{\frac{1}{2}}+T^{\frac{1}{2}}}
\end{aligned}
$$


The first-order condition is

$$
\frac{\partial \Pi}{\partial e_{1}}=b_{1}-4 T w^{\frac{1}{2}} b_{2}^{\frac{1}{2}} \frac{\frac{1}{2}\left(T-e_{1}\right)^{-\frac{1}{2}}}{\left\{\left(T-e_{1}\right)^{\frac{1}{2}}+T^{\frac{1}{2}}\right\}^{2}}=0
$$

Setting $x=\left(T-e_{1}\right)^{\frac{1}{2}}$ yields

$$
b_{1}\left\{x+T^{\frac{1}{2}}\right\}^{2}-2 T w^{\frac{1}{2}} b_{2}^{\frac{1}{2}} \frac{1}{x}=0
$$

or

$$
x^{3}+a x^{2}+d x+c=0
$$

with $a=2 T^{\frac{1}{2}}, d=T, \quad c=-2 T w^{\frac{1}{2}} \frac{b_{2}^{\frac{1}{2}}}{b_{1}}$.

The solution of this cubic equation is given by standard formulas:

$$
\begin{aligned}
p & =\frac{3 b-d^{2}}{3}=-\frac{T}{3} \\
q & =c+\frac{2 d^{3}}{27}-\frac{d b}{3}=c-\frac{2}{27} T^{\frac{3}{2}} \\
D & =\left(\frac{P}{3}\right)^{3}+\left(\frac{q}{2}\right)^{2}=\frac{c^{2}}{4}-\frac{c}{27} T^{\frac{3}{2}}
\end{aligned}
$$

Since $c<0$ we have $D>0$ and one real solution exists:

$$
x_{1}^{*}=-\frac{a}{3}+\left(-\frac{q}{2}+D^{\frac{1}{2}}\right)^{\frac{1}{3}}+\left(-\frac{q}{2}-D^{\frac{1}{2}}\right)^{\frac{1}{3}}
$$

which yields

$$
e_{1}^{*}=T-\left(-\frac{2 T^{\frac{1}{2}}}{3}+\left(-\frac{q}{2}+D^{\frac{1}{2}}\right)^{\frac{1}{3}}+\left(-\frac{q}{2}-D^{\frac{1}{2}}\right)^{\frac{1}{3}}\right)^{2}
$$

The associated income level is determined by $\tilde{y}_{1}$.

In the second step, we observe that the worker is indifferent between different effort levels if he is offered the compensation schedule satisfying the PC over the lifetime $y_{1}=\frac{4 w T}{\left(\left(T-e_{1}\right)^{\frac{1}{2}}+T^{\frac{1}{2}}\right)^{2}}-w$.

Future higher utility from the ratchet effect is offset by lower income in the first period. To ensure that the worker does not go beyond $e_{1}^{*}$, the firm can cap income at $\tilde{y}_{1}$, which 
we incorporate into the compensation schedule. An indifferent worker who acts in the interest of the firm would choose $e_{1}^{*}$, even with no upper bounds on income, so the cap is not strictly necessary.

\section{Proof of proposition 4:}

The comparison between $\hat{e}_{1}$ and $e_{1}^{*}$ yields that $\hat{e}_{1}>e_{1}^{*}$ is equivalent to

$$
w^{\frac{1}{2}} b_{1}^{-\frac{1}{2}} T^{\frac{1}{2}}<\left(-\frac{2 T^{\frac{1}{2}}}{3}+\left(-\frac{q}{2}+D^{\frac{1}{2}}\right)^{\frac{1}{3}}+\left(-\frac{q}{2}-D^{\frac{1}{2}}\right)^{\frac{1}{3}}\right)^{2}
$$

Observe that for $c<0$

$$
\left(-\frac{q}{2}+D^{\frac{1}{2}}\right)^{\frac{1}{3}}+\left(-\frac{q}{2}-D^{\frac{1}{2}}\right)^{\frac{1}{3}}>\frac{2 T^{\frac{1}{2}}}{3}
$$

since the left side monotonically declines with $c$, and is equal to $\frac{2 T^{\frac{1}{2}}}{3}$ for $c$ to equal 0 . Observe that $e_{1}^{*}$ decreases monotonically with $b_{2}$. For $b_{2}=0$ we have $c=0$ and $e_{1}^{*}=T$. For a sufficiently large amount for $b_{2}$, we obtain $e_{1}^{*}=0$. Since $\hat{e}_{1}$ is independent of $b_{2}$, the first and second assertion of the proposition follow.

\section{Proof of proposition 5:}

We start by showing that

$$
\begin{aligned}
\Pi^{n f}\left(b_{1}, b_{2}\right) & <\Pi^{f}\left(b_{1}\right) \text { for } b_{1}=b_{2} . \\
\Pi^{f}\left(b_{1}\right)-\Pi^{n f}\left(b_{1}, b_{2}\right) & =w-4 \sqrt{T b w}+3\left(T^{2} b_{2} b_{1} w\right)^{\frac{1}{3}} \\
& =\frac{1}{T b}\left\{\frac{w}{T b}-4 \sqrt{\frac{4}{T b}}+3\left(\frac{w}{T b}\right)^{\frac{1}{3}}\right\} \\
& =\frac{1}{T b}\left\{x-4 x^{\frac{1}{2}}+3 x^{\frac{1}{3}}\right\}
\end{aligned}
$$


when we set $x=w / T b)$. Since $w<T b$ we have $0<x<1$. It remains to show that $\Delta \equiv x-4 x^{1 / 2}+3 x^{1 / 3}>0$. Setting $y=x^{1 / 6}$ yields

$$
\Delta=y^{6}-4 y^{3}+3 y^{2}=y^{2}(y-1)^{2}\left(y^{2}+2 y+3\right)>0 .
$$

Hence, $\Pi^{n f}<\Pi^{f}$ for $b_{1}=b_{2}$. We next calculate

$$
\begin{aligned}
\frac{\partial \Pi^{n f}}{\partial b_{2}} & =T-T^{\frac{2}{3}} b_{1}^{\frac{1}{3}} b_{2}^{-\frac{2}{3}} w^{\frac{1}{3}} \\
& =T\left(1-\left(\frac{w}{T b_{1}}\right)^{\frac{1}{3}}\left(\frac{b_{1}}{b_{2}}\right)^{\frac{2}{3}}\right)
\end{aligned}
$$

Since $\frac{w}{T b_{1}}<1$ and $\frac{b_{1}}{b_{2}}<1$ for $b_{2} \geq b_{1}$ we obtain $\frac{\partial \Pi^{n f}}{\partial b_{2}}>0$. Lastly, we have

$$
\lim _{b_{2} \rightarrow \infty} \Pi^{n f}=\infty
$$

Hence, by the mean value theorem, the assertion follows. 


\section{Notation}

$B_{i}$ Output in period $i$

$b_{i}$ Productivity factor in period $i$, or $B_{i} / e_{i}$

$C_{i}(\cdot)$ Compensation contract offered by firm for output in period $i$

$e_{i}$ Worker's effort in period $i$

$e_{1}^{0}$ Worker's optimal effort in period 1 under firm's contract with incomplete monopsony power and worker rehired in period 2

$e_{1}^{f}$ Worker's optimal effort in period 1 under firm's contract with incomplete monopsony power, worker is fired in period 2 , and $\alpha=1 / 2$

$e_{1}^{n f}$ Worker's optimal effort in period 1 under firm's contract with incomplete monopsony power, worker is rehired in period 2 , and $\alpha=1 / 2$

$e_{1}^{*}$ Worker's optimal effort in period 1 under firm's contract with perfect monopsony power and worker rehired in period 2

$e_{2}^{0}$ Worker's optimal effort in period 2 under firm's contract with incomplete monopsony power and worker rehired in period 2

$\hat{e}_{1}$ Worker's optimal effort in period 1 under firm's contract with incomplete monopsony power and worker replaced in period 2

$T$ Upper bound on the worker's effort

$U$ Utility function of worker

$w$ Initial wealth of worker

$y_{i}$ Income in period $i$

$y_{2}^{0}$ Worker's income in period 2 under firm's contract with imperfect monopsony power and worker rehired in period 2 
$\hat{e}_{1}$ Worker's income in period 1 under firm's contract with imperfect monopsony power and worker replaced in period 2

$y_{1}^{*}$ Worker's income in period 1 under firm's contract with perfect monopsony power and worker rehired in period 2

$\alpha$ Parameter in Cobb-Douglas utility function

$\Pi_{t}$ Firm's profits in period $t$

$\Pi$ Sum of firm's profits over two periods 


\section{References}

[1] Abowd, J., F. Kramarz, and D. Margolis (2000) "High-wage workers and high-wage firms. Econometrica, 67: 251-333.

[2] Altonji, Joseph G. and Nicolas Williams (1998) "The effects of labor market experience, job seniority, and job mobility on wage growth. Research in Labor Economics 17: 233-276.

[3] Aron, Debra J. (1987) "Worker reputation and productivity incentives." Journal of Labor Economics, 5(4): 87-106.

[4] Attanasio, Orazio and Hilary Hoynes (2000) "Differential mortality and wealth accumulation." Journal of Human Resources, 35(1): 1-29.

[5] Clark, Andrew E. (1999) "Are wages habit-forming? Evidence from micro data." Journal of Economic Behavior $\&$ Organization, 39(2): 179-200.

[6] Economist (2002) "How to pay bosses." Economist, November 16.

[7] Fudenberg, D., B. Holmstrom, and P. Milgrom (1990) "Short-term contracts and long-term agency relationships." Journal of Economic Theory, 51: 131.

[8] Gibbons, Robert (1987) "Piece-rate incentive schedules." Journal of Labor Economics, 5(4): 413-429.

[9] Gibbons, Robert and Kevin Murphy (1992) Optimal incentive contracts in the presence of career concerns: Theory and evidence. Journal of Political Economy, 100(3): 468-505.

[10] Haegeland, T., and T.J. Klette (1999) "The creation and analysis of employeremployee matched data, pp. 231-259, in Contributions to Economic Analysis, vol. 241. Amsterdam; New York and Oxford: Elsevier Science, North-Holland. 
[11] Hellerstein, J.K., D. Neumark, and K.R. Troske (1996) "Wages, productivity and worker characteristics: Evidence from plant-level production functions and wage equations. Journal of Labor Economics, 17(3): 409-446.

[12] Hutchens, Robert M. (1989) "Seniority, wages and productivity: A turbulent decade. Journal of Economic Perspectives 3(4): 49-64.

[13] Kanemoto, Yoshitsugu, and Bentley MacLeod (1992) "The ratchet effect and the market for secondhand workers." Journal of Labor Economics, 10: 85-98.

[14] Lazear, Edward (1979) "Why is there mandatory retirement?" Journal of Political Economy, 87: 12611284.

[15] Lazear, Edward (1986) "Salaries and piece rates." Journal of Business, 59: 405431.

[16] Medoff, James L. and Katherine G. Abraham (1980) "Experience, performance and earnings. Quarterly Journal of Economics, 95(4): 703-736. 